\title{
FAKTOR-FAKTOR YANG MEMPENGARUHI KONSUMSI KOPI BUBUK 1001 DI KOTA BENGKULU
}

\section{FACTORS AFFECTING CONSUMPTION OF 1001 COFFEE POWDER IN BENGKULU CITY}

\author{
Herri Fariadi,, Beni Saputra \\ Program Studi Agribisnis Fakultas Pertanian Universitas Dehasen Bengkulu
}

\begin{abstract}
ABSTRAK
Saat ini, Indonesia merupakan produsen dan juga sekaligus konsumen penting komoditas kopi. Provinsi Bengkulu merupakan provinsi ke 4 di Sumatera dengan jumlah produksi kopi terbanyak, dengan luas lahan 75.922 Ha dengan total produksi 56.556 ton. Dari jumlah tersebut ada yang menjadi berbagai olahan kopi bubuk, adapun salah satu olahan kopi bubuk yang cukup terkenal di Kota Bengkulu adalah kopi bubuk 1001. Tujuan dari penelitian ini adalah: menganalisis konsumsi kopi bubuk 1001 di Kota Bengkulu dan mengetahui faktor-faktor yang mempengaruhi konsumsi kopi bubuk 1001 di Kota Bengkulu.

Metode penelitian yang digunakan untuk menganalisis konsumsi kopi bubuk 1001 di Kota Bengkulu adalah analisis deskriptif. Untuk mengetahui faktor-faktor yang mempengaruhinya konsumsi kopi bubuk 1001 dengan dianalisis dengan alat analisis regresi linear berganda. sampel yang digunakan dalam penelitan ini adalah sebanyak 78 responden, dilakukan dengan metode accidental sampling.

Hasil penelitian menunjukkan konsumsi kopi bubuk 1001 di Kota Bengkulu masih kategori rendah, hal ini ditunjukkan dengan nilai rata-rata konsumsi 260 gr/bln. Hasil uji secara simultan besarnya pengaruh 7 variabel $X$ terhadap konsumsi kopi bubuk 1001 secara bersama-sama berpengaruh signifikan. Sedangkan untuk uji parsial faktor yang berpengaruh nyata terhadap konsumsi kopi bubuk 1001 di Kota Bengkulu adalah selera (X1), harga kopi bubuk 1001 (X2), jumlah tanggungan keluarga (X6) dan jenis kelamin (X7).
\end{abstract}

Kata kunci : konsumsi, kopi bubuk 1001

\section{ABSTRACT}

At present, Indonesia is a producer and also an important consumer of coffee commodities. Bengkulu Province is the 4th province in Sumatra with the highest number of coffee production, with an area of 75,922 hectares with a total production of 56,556 tons. Of this amount there is a variety of processed coffee powder, as for one of the most well-known processed coffee in Bengkulu City is 1001coffee powder. The purpose of this study is to analyze the consumption of 1001 coffee powder in Bengkulu City and determine the factors that influence consumption 1001 coffee powder in the city of Bengkulu.

The research method used to analyze 1001 coffee powder consumption in Bengkulu City is descriptive analysis. To find out the factors that influence the consumption of 1001 coffee powder by being analyzed by means of multiple linear regression analysis. The sample used in this research was 78 respondents, conducted by accidental sampling method.

The results showed the consumption of 1001 coffee powder in Bengkulu City was still in the low category, this was indicated by the average value of consumption of $260 \mathrm{gr} / \mathrm{mo}$. Simultaneous test results of the effect of 7 variables $X$ on the consumption of 1001 coffee 
powder together have a significant effect. As for the partial test the factors that significantly influence the consumption of 1001 coffee powder in Bengkulu City are taste (X1), price of 1001 coffee powder (X2), number of dependents of the family (X6) and gender (X7).

Keywords : consumtion, 1001 coffee powder

\section{PENDAHULUAN}

\section{Latar Belakang}

Saat ini, Indonesia merupakan produsen dan juga sekaligus konsumen penting komoditas kopi. Sebagai produsen, Indonesia menempati urutan keempat setelah Brasil, Vietnam dan Kolombia, dan sebagai konsumen berada dalam urutan ketujuh (ICO, 2017). Bagi masyarakat Indonesia pada umumnya, minum kopi telah menjadi bagian dari kehidupan sehari-hari terutama bagi orang-orang tua dan sekarang juga anakanak muda dan remaja (Kementrian Perindustrian, 2017).

Provinsi Bengkulu merupakan provinsi ke 4 di Sumatera dengan jumlah produksi kopi terbanyak, dengan luas lahan 75.922 Ha dengan total produksi 56.556 ton. Kopi Robusta merupakan kopi yang paling banyak dihasilkan yaitu sebesar 54.921 ton dan 1.635 ton adalah kopi Arabika (Direktorat Jendral Perkebunan, 2016). Dari jumlah tersebut kopi yang dihasilkan dipasarkan di berbagai daerah, serta ada yang menjadi berbagai olahan kopi bubuk di kota Bengkulu, adapun salah satu olahan kopi bubuk yang cukup terkenal di Kota Bengkulu adalah kopi bubuk 1001.

Kopi 1001 adalah kopi bubuk Robusta yang banyak diminati oleh masyarakat Kota Bengkulu, hal ini dapat dilihat dari banyaknya jumlah kopi 1001 yang tersedia di tengah-tengah masyarakat, kopi 1001 dapat dengan mudah dijumpai diwarung-warung kecil, pertokoan, dan pasar. Begitupun daya beli masyarakat terhadap kopi 1001 cukup tinggi, hal ini sesuai dengan observasi yang telah dilakukan bahwa rata-rata setiap warung bisa menjual kopi 1001 sampai 15 bungkus atau 675 gram per minggu. Berdasarkan latar belakang tersebut, maka perlu dikaji lebih dalam mengenai faktor-faktor yang mempengaruhi konsumsi kopi bubuk 1001 di Kota Bengkulu.

\section{METODE PENELITIAN}

\section{Tempat dan Waktu Penelitian}

Penelitian ini dilaksanakan secara purposive (sengaja) di Kota Bengkulu dimana kopi merk 1001 diproduksi di kota Bengkulu dan banyak dipasarkan di kota bengkulu. Waktu penelitian dilakukan pada bulan April 2019. 


\section{Jenis dan Sumber Data}

Data yang digunakan dalam penelitian ini adalah data primer dan data sekunder, Data primer adalah data yang dikumpulkan dari penduduk kota Bengkulu melalui wawancara, dan data sekunder diperoleh dari dinas terkait seperti Badan Pusat Statistik Kota Bengkulu, serta skripsi dan jurnal ilmiah yang berkaitan dengan judul penelitian.

\section{Penentuan Populasi dan Sampel}

Pengambilan sampel penelitian dilakukan dengan metode accidental sampling.. Kriteria penentuan sampel yang akan diambil adalah masyarakat Kota Bengkulu. Untuk mempermudah penentuan jumlah sampel yang akan diteliti, maka ditentukan dengan menggunakan metode Slovin dengan rumus sebagai berikut:

$$
n=\frac{N}{1+N e^{2}}
$$

Keterangan:

$\mathrm{N} \quad$ : Besaran sampel

$\mathrm{N} \quad$ : Besaran populasi

e $\quad$ :Margin of error atau kesalahan

maksimum yang bisa ditoleransi,

biasanya Sebesar $10 \%$

Adapun jumlah penduduk Kota

Bengkulu pada tahun 2017 adalah 368.065 jiwa (BPS, 2019). Untuk menentukan jumlah sampel maka dilakukan perhitungan sebagai berikut :

$$
\begin{gathered}
n=\frac{N}{1+N e^{2}} \\
n=\frac{368.065}{1+368.065(0,1)^{2}} \\
n=\frac{368.065}{1+368.065(0,01)} \\
n=\frac{368.065}{4,680} \\
n=78
\end{gathered}
$$

Maka sampel yang digunakan dalam penelitan ini adalah sebanyak 78 responden.

\section{Metode Analisis Data}

Untuk menentukan tingkat konsumsi kopi bubuk 1001 di Kota Bengkulu adalah dengan menggunakan penggolongan tiga versi yaitu tinggi, sedang, rendah. Dimana untuk menentukan tingkat konsumsi tersebut dilihat dari konsumsi tertinggi dikurangi konsumsi ter rendah dan dibagi tiga, yang ditampilkan dalam bentuk tabel.

Faktor-faktor yang mempengaruhi konsumsi kopi bubuk 1001 dianalisis dengan alat analisis regresi linear berganda. Secara sistematis model yang digunakan adalah sebagai berikut:

$\mathrm{Y}=\mathrm{a}+\mathrm{b} 1 \mathrm{X}_{1}+\mathrm{b}_{2} \mathrm{X}_{2}+\mathrm{b} 3 \mathrm{X}_{3}+\mathrm{b} 4 \mathrm{X}_{4}+\mathrm{b} 5 \mathrm{X} 5+\mathrm{b} 6 \mathrm{X6}+\mathrm{b} 7 \mathrm{X} 7+\mathrm{e}$

Keterangan :

$\mathrm{Y}=$ Jumlah Konsumsi Kopi bubuk 1001 (kg/bulan)

Bo $=$ Konstanta

$\mathrm{X} 1=$ Selera

$\mathrm{X} 2$ = Harga Kopi $1001(\mathrm{Rp} / \mathrm{kg})$ 
$\mathrm{X} 3=$ Harga Gula Pasir $(\mathrm{Rp} / \mathrm{kg})$

$\mathrm{X} 4=$ Harga Kopi Instan (Rp/bungkus)

$\mathrm{X} 5=$ Tingkat Pendapatan $(\mathrm{Rp})$

$\mathrm{X} 6$ = Jumlah Tanggungan Keluarga

$\mathrm{X} 7=$ Jenis Kelamin

b1-b7= koofisien regresi

$\mathrm{e}=$ error

\section{HASIL DAN PEMBAHASAN}

\section{Tingkat Konsumsi Kopi}

Berdasakan hasil penelitian tingkat kosumsi kopi bubuk 1001 di Kota Bengkulu dapat dilihat pada Tabel 1.

Berdasarkan tabel 1 terdapat tiga kategori tingkat konsumsi yaitu tinggi, sedang dan rendah. Tingkat konsumsi terbanyak adalah kategori rendah dengan konsumsi 45-280 gr/bln. Adapun rata-rata konsumsi kopi bubuk 1001 adalah di Kota Bengkulu 260 gr/bln.

Hal ini disebabkan terdapat perbedaan yang signifikan terhadap konsumsi kopi bubuk 1001 di Kota Bengkulu antara laki-laki dan perempuan. Dari 78 responden 36 orang merupakan perampuan, dan 42 orang adalah laki-laki, berdasarkan hasil penelitian yang didapatkan tingkat konsumsi laki-laki terhadap kopi bubuk 1001 lebih tinggi dibandingkan dengan perempuan, hal ini juga didukug oleh hasil uji statistik t yang menunjukkan bahwa jenis kelamin berpengaruh positif terhadap konsumsi kopi bubuk 1001.

\section{Faktor-faktor yang Mempengaruhi}

\section{Konsumsi Kopi Bubuk 1001}

Analisis regresi linear berganda digunakan untuk menganalisis faktorfaktor yang mempengaruhi konsumsi kopi bubuk 1001 di Kota Bengkulu. Pengolahan data dengan menggunakan perangkat lunak (software) komputer program Microsoft Exceldan Statistic Packagefor Social Sciences (SPSS) versi 16.0. Pengujian parameter dilakukan pada tingkat taraf nyata $5 \%$ hasil dari analisis regresi linear berganda dapat dilihat pada Tabel 2 .

Tabel 1. Tingkat Konsumsi Kopi 1001 di Kota Bengkulu

\begin{tabular}{|l|l|c|c|c|}
\hline No & $\begin{array}{c}\text { Kategori Konsumsi } \\
(\mathbf{g r} / \mathbf{b l n})\end{array}$ & Jumlah (Jiwa) & Persentase (\%) & $\begin{array}{c}\text { Rata-rata } \\
\text { (gr/bln) }\end{array}$ \\
\hline 1 & Tinggi (516-750) & 7 & 9 & \\
\cline { 1 - 3 } 2 & Sedang (281-515) & 24 & 31 & \\
\cline { 1 - 3 } 3 & Rendah (45-280) & 47 & 60 & \multirow{2}{*}{260} \\
\hline
\end{tabular}

Sumber : Olahan Data Primer 2019 
Tabel 2. Nilai Parameter Analisis Regresi Linier Berganda (Coefficientsa)

\begin{tabular}{|c|c|c|c|c|c|}
\hline \multirow[b]{2}{*}{ Model } & \multicolumn{2}{|c|}{ Unstandardized Coefficients } & \multirow{2}{*}{$\frac{\text { Standardized Coefficients }}{\text { Beta }}$} & \multirow[b]{2}{*}{$\mathrm{T}$} & \multirow[b]{2}{*}{ Sig. } \\
\hline & $B$ & Std. Error & & & \\
\hline 1 (Constant) & 626.728 & 491.478 & & 1.275 & 0.206 \\
\hline Selera & 98.465 & 32.201 & 0.244 & 3.058 & 0.003 \\
\hline harga kopi 1001 & -0.297 & 0.051 & -0.378 & -5.875 & 0.000 \\
\hline harga gula pasir & 0.026 & 0.038 & 0.035 & 0.690 & 0.492 \\
\hline harga kopi instan & -0.059 & 0.033 & -0.095 & -1.756 & 0.083 \\
\hline Pendaptan & 4.787E-6 & 0.000 & 0.017 & 0.307 & 0.760 \\
\hline t keluarga & 90.090 & 17.729 & 0.348 & 5.081 & 0.000 \\
\hline jenis kelamin & 53.026 & 23.375 & 0.134 & 2.269 & 0.026 \\
\hline
\end{tabular}

Output di atas dapat diperoleh persamaan regresi sebagai berikut :

$\mathrm{Y}=\mathrm{a}+\mathrm{b}_{1} \mathrm{X}_{1}+\mathrm{b}_{2} \mathrm{X}_{2}+\mathrm{b}_{3} \mathrm{X}_{3}+\mathrm{b}_{4} \mathrm{X}_{4}+\mathrm{b}^{\mathrm{X}} \mathrm{X} 5+\mathrm{b} 6 \mathrm{X} 6+\mathrm{b} 7 \mathrm{X} 7+\mathrm{e}$ Keterangan :

$$
\begin{array}{ll}
\text { a } & : \text { Konstanta } \\
\mathrm{e} & : \text { Error } \\
\mathrm{Y} & : \text { Konsumsi kopi bubuk } 1001 \\
\mathrm{~b} 1-\mathrm{b} 7 & : \text { Koofisien Determinasi } \\
\mathrm{Y} & : 626.782+98.465+-0.297+ \\
& 0.026+-0.059+4.787 \mathrm{E}-6+ \\
& 90.090+53.026+\mathrm{e}
\end{array}
$$

\section{a) Nilai konstanta}

Nilai konstanta adalah 626.782 jika tidak terjadi perubahan terhadap selera, harga kopi 1001, harga gula pasir, harga kopi instan, tingkat pendapatan, jumlah tanggungan keluarga, serta jenis kelamin, maka konsumsi kopi bubuk 1001 di Kota Bengkulu akan meningkat sebesar $626.782 \mathrm{gr}$ b) Nilai b1 (selera (X1))

Nilai b1 (selera) adalah 98.465 mempunyai arti bahwa jika terjadi kenaikan $1 \%$ selera atau kebiasaan, maka konsumsi kopi bubuk 1001 akan naik sebesar $98.465 \mathrm{gr}$

c) Nilai b2 (harga kopi bubuk 1001

(X2))

Nilai b2 (harga kopi bubuk 1001) -0.297 mempunyai arti bahwa jika terjadi kenaikan $1 \%$ harga kopi bubuk 1001, maka konsumsi kopi bubuk 1001 akan turun sebesar $-0.297 \mathrm{gr}$

\section{d) Nilai b3 (harga gula pasir (X3))}

Nilai b3 (harga gula pasir) 0.026 mempunyai arti bahwa jika terjadi kenaikan $1 \%$ harga gula pasir, maka konsumsi gula pasir akan naik sebesar $0.026 \mathrm{gr}$ 
e) Nilai b4 (harga kopi instan (X4))

Nilai b4 (harga kopi instan) -0.059 mempunyai arti bahwa jika terjadi kenaikan $1 \%$ harga kopi instan maka konsumsi kopi instan akan turun sebesar 0.059 bungkus.

\section{f) Nilai b5 (tingkat pendapatan (X5) )}

Nilai b5 (tingkat pendapatan) 4.787E-6 mempunyai arti bahwa jika terjadi kenaikan $1 \%$ tingkat pendapatan maka pendapatan akan naik sebesar Rp 4.787

g) Nilai b6 (jumlah tanggungan keluarga (X6) )

Nilai b6 (jumlah tanggungan keluarga) 90.090 mempunyai arti bahwa jika terjadi kenaikan $1 \%$ jumlah tanggungan keluarga maka konsumsi kopi bubuk 1001 akan naik sebesar 90.090 gr h) Nilai b7 (jenis kelamin (X7) )

Nilai b7 (jenis kelamin) 53.026 mempunyai arti bahwa jika terjadi kenaikan $1 \%$ jumlah jenis kelamin maka konsumsi kopi bubuk 1001 akan naik sebesar 53.026 gr

\section{Uji F}

Hasil uji F dapat dilihat pada tabel 3. Berdasarkan uji statistik pada Tabel 3 menunjukkan bahwa hasil analisis diperoleh tingkat signifikansi .000 lebih kecil dari $\alpha=0.05$ atau $\mathrm{f}$ hitung sebesar 48.427 lebih besar dari f tabel 2.10 hal ini menunjukkan bahwa seluruh variabel bebas (X) yang dimasukkan ke dalam model secara bersama-sama menunjukkan pengaruh nyata terhadap variabel tetap (Y) konsumsi kopi bubuk 1001 di Kota Bengkulu.

\section{Uji Koofisien Determinasi R}

Koefisien determinasi digunakan untuk menguji ketepatan model. Nilai koefisien determinasi padahasilregresi dapat dilihat pada Tabel 4.

Tabel 3. Uji F (ANOVA ${ }^{b}$ )

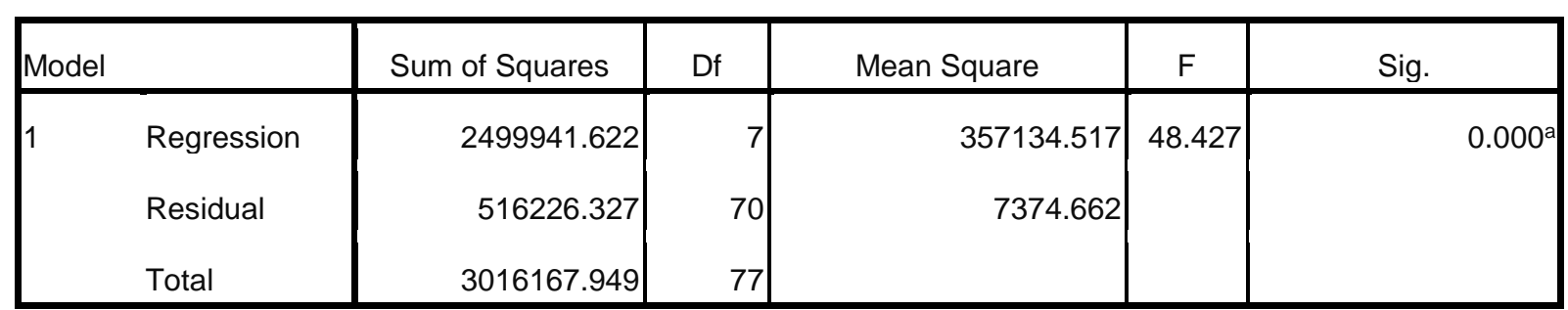


Berdasarkan Tabel 4 maka dapat diketahui nilai koefisien determinasi $\left(\mathrm{R}^{2}\right)$ sebesar 0.829 yang berarti bahwa $82.9 \%$ keragaman variabel tak bebas (Y) dapat dijelaskan atau dapat diterangkan oleh keragaman variabel bebas $(\mathrm{X})$ dan sisanya sebanyak 17.1 persen dijelaskan oleh variabel lain yang tidak termasuk dalam model.

Hasil analisis diperoleh nilai koefisien korelasi (R) konsumsi kopi bubuk 1001 sebesar 0.910 dengan tanda positif dan mendekati 1, maka dapat diartikan bahwa antara variabel tak bebas (Y) mempunyai hubungan eratdengan seluruh variabelbebas $(\mathrm{X})$

\section{Uji T}

Uji statistik pada dasarnya untuk menunjukan seberapa jauh pengaruh satu variabel independen secara individual dalam menerangkan variasi variabel dependen. Uji statistik t dapat dilihat pada tabel 5 .

Tabel 4. Uji Statistik Determinasi R (Model Summaryb)

\begin{tabular}{|l|c|c|c|c|c|}
\hline Model & $\mathrm{R}$ & $\mathrm{R}$ Square & Adjusted R Square & $\begin{array}{c}\text { Std. Error of the } \\
\text { Estimate }\end{array}$ & Durbin-Watson \\
\hline 1 & $0.910^{\mathrm{a}}$ & 0.829 & 0.812 & 85.87585 & 1.930 \\
\hline
\end{tabular}

Tabel 5. Uji Statistik T

\begin{tabular}{|l|r|r|}
\hline Model & $\mathrm{T}$ & \multicolumn{2}{|c|}{ Sig. } \\
\hline $1 \quad$ (Constant) & 1.275 & 0.206 \\
Selera & 3.058 & 0.003 \\
harga kopi 1001 & -5.875 & 0.000 \\
harga gula pasir & 0.690 & 0.492 \\
harga kopi instan & -1.756 & 0.083 \\
Pendaptan & 0.307 & 0.760 \\
t keluarga & 5.081 & 0.000 \\
jenis kelamin & 2.269 & 0.026 \\
\hline
\end{tabular}




\section{Selera $(\mathrm{X1})$}

Berdasarkan uji statistik pada Tabel11 koefisien diatas dapat diketahui bahwa nilai signifikan untuk variabel selera sebesar 0.003 . Nilai signifikan lebih kecil dari nilai probabilitas (0.05) atau nilai $0.003<0,05$, maka $\mathrm{H} 0$ ditolak. Atau variabel selera memiliki nilai $\mathrm{t}$ hitung $=$ $3.058>\mathrm{t}$ tabel $=1.997$ yang artinya selera berpengaruh nyata terhadap konsumsi kopi bubuk 1001. Berdasarkan hasil penelitian yang didapatkan bahwa responden yang menyukai kopi bubuk 1001 tingkat konsumsinya lebih tinggi jika dibandingkan dengan responden yang tidak menyukai kopi bubuk 1001 .

\section{Harga kopi 1001 (X2)}

Berdasarkan Tabel koefisien diatas dapat diketahui bahwa nilai signifikan untuk variabel harga kopi 1001 sebesar 0.000.Nilai signifikan lebih kecil dari nilai probabilitas (0.05) atau nilai $0.000<0.05$, maka H1diterima. Atau variabel harga kopi 1001 memilikinilait hitung $=$ $5.875>\mathrm{t}$ tabel $=-1.997 \mathrm{yang}$ artinya harga kopi 1001 mempengaruhi konsumsi kopi bubuk 1001. Hasil penelitian yang telah dilakukan menunjukkan variabel harga (X2) berpengaruh negatif terhadap konsumsi kopi 1001, berdasarkan keterangan yang didapatkan pada responden apabila terjadi peningkatan harga pada kopi bubuk 1001, maka akan terjadi penurunan tingkat konsumsi terhadap kopi bubuk 1001.

\section{Harga gula pasir (X3)}

Berdasarkan Tabel koefisien diatas dapat diketahu ibahwa nilai signifikan untuk variabel harga gula pasir 0.492 . Nilai signifikan lebih besar dari nilai probabilitas $(0.05)$ atau nilai $0.492>0.05$, maka H0 diterima. Atau variable harga harga gula pasir memiliki nilai $\mathrm{t}$ hitung $=$ $0.987<\mathrm{t}$ tabel $=1.997$ yang artinya harga gula pasir tidak mempengaruhi konsumsi kopi bubuk 1001. Berdasarkan informasi yang didapatkan dari responden bahwa apabila terjadi peningkatan harga pada gula pasir mereka akan tetap mengkonsumsi kopi dan harga gula pasir tidak mempengaruhi tingkat konsumsi mereka terhadap kopi bubuk 1001.

\section{Harga kopi instan (X4)}

Berdasarkan Tabel koefisien diatas dapat diketahui bahwa nilai signifikan untuk variabel harga kopi instan 0.083 . Nilai signifikan lebih besar dari nilai probabilitas (0.05) atau nilai 0.083>0.05,maka H0 diterima. Atau variable harga kopi instan memiliki nilait hitung $=-1.756<\mathrm{t}$ tabel $=-1.997$ yang artinya harga kopi instan tidak mempengaruhi konsumsi kopi bubuk 
1001. Berdasarkan keterangan yang diberikan responden bahwa apabila terjadi perubahan harga naik atau turun pada produk kopi instan mereka akan tetap mengkonsumsi kopi bubuk 1001.

\section{Tingkat Pendapatan (X5)}

Berdasarkan koefisien diatas dapat diketahui bahwa nilai signifikan untuk variabel tingkat pendapatan sebesar 0.760. Nilai signifikan lebih besar dari nilai probabilitas $(0.05)$ atau nilai 0.760 $>0,05$, maka H0 diterima. Atau variable tingkat pendapatan memiliki nilai t hitung $=0.307<\mathrm{t}$ tabel $=1.997$ yang artinya tingkat pendapatan tidak mempengaruhi konsumsi kopi bubuk 1001. Berdasarkan keterangan yang didapatkan pada responden yang mengkonsumsi kopi bubuk 1001, bahwa tinggi atau rendahnya pendapatan tidak mempengaruhi mereka untuk mengkonsusmsi kopi 1001.

\section{Jumlah tanggungan keluarga (X6)}

Berdasarkan Tabel koefisien diatas dapat diketahui bahwa nilai signifikan untuk variabel jumlah tanggungan keluarga sebesar 0.000. Nilai signifikan lebih kecil dari nilai probabilitas (0.05) atau nilai $0.000<0.05$, maka $\mathrm{H} 0$ ditolak. Atau variable jumlah tanggungan keluarga memiliki nilait hitung $=5.081>\mathrm{t}$ tabel $=$ 1.997yang artinya jumlah tanggungan keluarga berpengaruh signifikan terhadap konsumsi kopi bubuk 1001. Berdasarkan keterangan yang didapatkan dari responden bahwa faktor tanggungan keluarga mempengaruhi mereka dalam mengkonsumsi kopi 1001.

\section{Jenis kelamin (X7)}

Berdasarkan Tabel koefisien diatas dapat diketahui bahwa nilai signifikan untuk variabel jenis kelamin sebesar 0.026. Nilai signifikan lebih kecil dari nilai probabilitas $(0.05)$ atau nilai $0.026<0.05$, maka H1diterima. Atau variable jenis kelamin memiliki nilait hitung $=2.269>\mathrm{t}$ tabel $=1.997$ yang artinya jenis kelamin mempengaruhi konsumsi kopi bubuk 1001. Berdasarkan hasil penelitian yang dilakukan terhadap responden, responden laki-laki memiliki tingkat konsumsi lebih tinggi terhadap kopi bubuk 1001 dibandingkan dengan perempuan.

\section{KESIMPULAN}

1. Konsumsi kopi bubuk 1001 di Kota Bengkulu masih kategori rendah, hal ini ditunjukkan dengan nilai rata-rata konsumsi $260 \mathrm{gr} / \mathrm{bln}$.

2. Hasil uji secara simultan besarnya $\begin{array}{lllll}\text { pengaruh } & 7 & \text { variabel } & X & \text { terhadap }\end{array}$ konsumsi kopi bubuk 1001 secara bersama-sama berpengaruh signifikan. 
Sedangkan untuk uji parsial faktor yang berpengaruh nyata terhadap konsumsi kopi bubuk 1001 di Kota Bengkulu adalah selera (X1), harga kopi 1001 (X2), jumlah tanggungan keluarga (X6) dan Jenis Kelamin.

\section{DAFTAR PUSTAKA}

Badan Pusat Statistik. 2018. Jumlah Penduduk Kota Bengkulu Tahun 2017. BPS. Bengkulu.

Direktorat Jendral Perkebunan. 2016. Kopi 2015-2017 Statistik perkebunan Indonesia. Ditjenbun. Jakarta.

Farama. firdhan. 2016. Faktor-Faktor Yang Mempengaruhi Permintaan Beras di Kota Kendari. Kendari.

Kementrian Perindustrian Republik Indonesia. 2017. Peluang Usaha IKM Kopi. KPRI. Jakarta.

Nadapdap, Badhu. 2007. Faktor- Faktor Yang Mempengaruhi Permintaan Rumah Tangga Terhadap Kopi. Universitas Hkbp Nommensen, Medan.
Nurmansyah M. 2006. Analisis FaktorFaktor Yang Mempengaruhi Keputusan Rumah Tangga Dalam Mengkonsumsi Daging Pasca Isu Flu Burung (Skripsi). Fakultas Pertanian, Institut Pertanian Bogor. Bogor.

Sanjaya, Agung Dkk. 2017. Faktor-Faktor Yang Mempengaruhi Konsumsi Cabai Rawit Di Kabupaten Semarang. Vol 13. No 1. Semarang Sitanggang, Iriyanti N. 2017. FaktorFaktor Yang Mempengaruhi Konsumsi Beras Di Kecamatan Berbak Kabupaten Tajabung Timur. Fakultas Pertanian. Universitas Jambi. Jambi

Sonata, Rizki. 2016. Kopi 1001 Asli Bengkulu. http://Rizkisonata.blogspot.com/20 16/12/14_9.html?m=1. (21 mei 2019)

Wahyudian, Dkk. 2004. Analisis faktorfaktor yang mempengaruhi konsumsi kopi dan analisis pemetaan beberapa merek kopi dan implikasinya pada pemasaran kopi. Vol 1. No 1. Jakarta. 